\title{
Singapore Convention on Mediation and Its Ratification in China
}

\author{
Yatian Yin* \\ The University of Sydney, Sydney NSW2006, Australia \\ *Corresponding author: Yatian Yin, ytiantian@live.cn
}

\begin{abstract}
China has signed the United Nations Convention on International Settlement Agreements Resulting from Mediation, namely the Singapore Convention on Mediation, on August 7, 2019, making it possible for China's domestic courts to resolve international commercial disputes by implementing settlement agreements resulting from international commercial mediation. Relying on the Belt and Road Initiative (BRI), numerous commercial mediation organizations have successively established and integrated mediation into the international commercial dispute resolution mechanism in making effort for the internationalization of China's commercial mediation system under the background of improving diversified dispute resolution mechanisms. Based on the status quo of commercial mediation in China, this article focuses on the connection and convergence between China's practice and the principle of the Convention, as well as discusses the rationality for its ratification.
\end{abstract}

Keywords: Singapore Convention on Mediation; Status quo of China's commercial mediation; Rationality; Ratification

Publication date: August 2021; Online publication: August 30, 2021

\section{Introduction}

As of June 1, 2021, there has been 53 signatories in the Singapore Convention on Mediation, and it has successively entered into force for 6 countries ${ }^{[1]}$. Although it has not yet been approved and ratified by the Standing Committee of the National People's Congress, China still has actively responded to its adoption and application as one of the first batch of signatories where the recognition and support of the convention and its function of promoting international commercial dispute resolution as well as international economic relations can be indicated. Chapter I presents the latest practical development and policies on international commercial mediation in China upon the basis of which rationality of its ratification is discussed in Chapter II.

\section{Chapter I. Status quo of commercial mediation in China: Development}

According to the Annual Review and Preview on Commercial Dispute Resolution in China as well as a series of publications organized and published by the Beijing Arbitration Commission/Beijing International Arbitration Center (BAC/BIAC), great efforts have been made in China on regulation adoption, system construction, internationalization, and online development in recent years upon which certain achievements have been made where commercial mediation system is increasingly becoming professional and internationalized.

Firstly, policy documents on commercial mediation have been continuously issued by competent authorities ${ }^{[2]}$. Decision of the Central Committee of the Communist Party of China (CPC) on Major Issues Concerning Comprehensively Advancing the Rule of Law (2014) proposed to improve the diversified 
dispute resolution mechanism organically connecting mediation, arbitration, administrative adjudication, administrative reconsideration, and litigation. Jointly issued by the General Offices of both the State Council and the CPC Central Committee, Opinions on Improving the Diversified Resolution Mechanism for Contradictions and Disputes (No. 60 [2015] of the General Office) proposed to promote the establishment of commercial mediation organizations in various field for providing professionalized services, promote the recognition and enforcement of mediation agreements, improve and constrain the skills and code of conduct of specially invited mediators, and enhance the professionalism of mediators as well as the credibility of mediation procedures, on the basis and guarantee of people's courts, pointing out the direction for the future development of commercial mediation in China, and at the same time, establishing a policy basis for future legislation. In addition, Opinions of the Supreme People's Court on Further Deepening the Reform of the Diversified Dispute Resolution Mechanism (No. 14 [2016] of the Supreme People's Court) and Provisions of the Supreme People's Court on Specially Invited Mediation by the People's Courts (Interpretation No. 14 [2016] of the Supreme People's Court) have successively provided a guiding basis for the promotion and application of commercial mediation and its professional construction.

Secondly, the integrated and comprehensive mediation system is being established ${ }^{[3]}$. In May 2019, the Ministry of Justice has put forward at the first ever national mediation work conference that an integrated and comprehensive mediation system featuring complementarity, convergence, and coordination would be fundamentally formed by the end of 2022. Fu Zhenghua, the former Minister of Justice, pointed out in his speech at the conference that it is necessary and vital to enhance the construction of industrial and professional mediation, as well as to vigorously develop commercial mediation in China, especially foreign-related ones, in directing for the next stage of work. Later in July, Opinions on Accelerating the Construction of Public Legal Service System, which is jointly issued by the General Offices of both the CPC Central Committee and the State Council, again clearly stated that the commercial mediation system should be highly improved.

Third, reform of the supporting system of commercial mediation has been carried out for optimization

[3]. According to the authorization of the Standing Committee of the National People's Congress, the Supreme People's Court has carried out the pilot work for the reform in promoting the split of complex and simple civil litigation procedures in some areas, measures of which includes optimizing the judicial recognition procedures of mediation agreements, reasonably broadening the scope of its application, perfecting rules of jurisdiction over cases in need, and improving the specially-invited mediation. Under such background, Shanghai, the pioneer of the reform and opening up as well as a window for China's opening and integration into the world, has actively innovated its construction of commercial mediation mechanism. Efforts have been made on all aspects, adhering to the principle of "mediation first" while improving the coordinating mechanism for litigation and mediation, accelerating the establishment of the one-stop diversified dispute resolution mechanism for foreign-related commercial disputes within which litigation, mediation, and arbitration are coordinately working, and promoting the construction of mediation organizations and mediators' team while innovating its operating method. The beneficial experience of Shanghai would provide not only a solid practical foundation for national promotion, but also guidance for the content of legislation.

Fourth, commercial mediation organizations have been gradually established and are becoming mature. The China Council for the Promotion of International Trade (CCPIT) Commercial Sub-Council was formally established on November 18, 2018, conducting mediation for commercial disputes in the service industry and consumer goods sector through offline and online modes upon application from domestic and 
foreign parties. The establishment of such a professional commercial mediation organization marks the official launch of the first national-leveled and international commercial mediation agency for the service industry and consumer goods sector in China. What is worth noting is that paragraph 2 of Article 1 of the Convention clearly excludes disputes arising from consumer relations from the scope of application. However, the CCPIT Mediation Center is only open to the service industry and consumer goods upon which, in future practice, we could look forward to cases related to the service industry in resolution of which the Convention is applicable. Also, in 2018, BRI International Commercial Mediation Center has successively established branches in free-trade zones of both Shaanxi and the Guangdong-Hong Kong-Macao Greater Bay Area (GBA) in deepening the service construction while integrating international commercial mediation into the Belt and Road service mechanism, aiming to create a peaceful and stable environment for trade and dispute resolution for participants of the BRI as well as to promote the high-quality development of the BRI in the perspective of legal services. Furthermore, the deepened interconnection would provide the Center with a broader operating platform and a clearer direction guidance. With the indepth development of the BRI, China's commercial mediation would be further enhanced in terms of professionalism and internationalization. In view of the COVID-19 pandemic, the online mediation model may become the main mode of international commercial dispute resolution in the post-epidemic era, in the context of which the capabilities and efficiency of online commercial mediation in China would be further improved. In 2019, Benchmark Chambers International \& Benchmark International Mediation Center (BCI \& BIMC) was formally in operation and committed to provide parties with internationalized and professionalized commercial mediation with enforcement guarantee, which is backed by the selection of high-quality mediators from around the world and online links with multiple courts around the nation. One more thing to notice is that Suzhou (Mediation) Working Group of Singapore International Mediation Centre (SIMC) has been established at Suzhou Industrial Park (SIP) to promote access to mediation as an avenue to resolve cross-border commercial disputes on February 19, 2021. Implementation of the world's leading mediation agency would also provide beneficial experience support and platform guarantee for the optimized development and internationalization of commercial mediation in China.

Fifth, the emergence of successful cases has injected vitality into the future development of commercial mediation. In regard to the people's courts, the Supreme People's Court and the people's courts at all levels have carried out mediation in litigation procedures of commercial disputes. In addition, numerous mediation organizations, representative of which should be CCPIT, have accepted applications for mediation and successfully resolved concerning disputes, which has laid a practical foundation for the development and promotion of online mediation as well as the model of connection of arbitration and mediation.

The research on China's commercial mediation system and its current operation situation aims to improve relevant regulations in China to promote the effective connection with the Singapore Convention on Mediation, and to realize the implementation of the settlement agreement resulting from commercial mediation under the framework of the Convention in China, on the basis of which would better serve the subjects of international commercial relationships and providing strong legal support for China's economic development.

\section{Chapter II. Ratification of the Singapore Convention on Mediation: Rationality}

There are scholars that refer international litigation, international arbitration, and international mediation as "international dispute resolution tourist destination" ${ }^{[4]}$, from which the great significance of mediation as one of the "foundation of international dispute resolution" can be demonstrated ${ }^{[5]}$. However, there would 
be no point in favoring mediation for dispute resolution without effective enforcement mechanism. This is the same principle of "no point in having arbitration-friendly laws, well-drafted arbitration rules, and competent arbitrators and counsel, if no effective enforcement mechanism is available, whether or not it is actually used ${ }^{[6] " . ~ E n f o r c e m e n t ~ i s ~ n o t ~ o n l y ~ a ~ m a n n e r ~ o f ~ e n s u r i n g ~ t h e ~ e f f e c t i v e n e s s ~ o f ~ t h e ~ m e d i a t i o n ~ p r o c e s s, ~}$ but it is also a key factor that favors the application of mediation in preference to other methods of international commercial dispute resolution ${ }^{[7]}$, which is the core and fundamental reason to the ratification and implementation of Singapore Convention on Mediation in China being so important and a requisite.

The entry into force of the Convention means that the capability of judicial enforcement of settlement agreements resulting from international commercial mediation has been improved, and their international liquidity has been enhanced, making the international commercial mediation system become another widely recognized international dispute resolution mechanism in the world along with the international judicial system and the international commercial arbitration system. In a global perspective, the adoption of the Singapore Convention on Mediation has created a brand-new path in regard to international law for peaceful settlements of international disputes, and it has started a new era of international commercial dispute resolution, which provides vital guarantees on international law for international trade. Moreover, in the post-pandemic era, where disputes have been predicted to be boomed, international commercial mediation and its effective enforcement would be a strong support not only for orderly development but also the recovery of both the global and domestic economy.

Domestically, ratification of the Convention has more solid ground. Ever since the Third Plenary Session of the $18^{\text {th }}$ CPC Central Committee, where the general reform goal of promoting the modernization of the national governance system and governance capabilities has been put forward, the requirement for a comprehensive reform in the legal area has arisen. The social governance on the track of the rule of law requires China to strengthen the authoritative role of law in rights relief and dispute resolution, in addition, to establish and improve the mechanisms for legitimate safeguarding of it. In the reform of diversified dispute resolution mechanism, commercial mediation has played an important role. Unique advantages such as high respect for the parties' autonomy of will, flexibility, convenience, high efficiency, and effectiveness have not only made commercial mediation to operate independently as a dispute resolution procedure to settle disputes, but they have also made it possible to connect and coordinate mediation with litigation and arbitration procedures, which would become the highlight of the diversified dispute resolution mechanism in China ${ }^{[8]}$.

With the development of BRI in a wider and larger scale, international trade practitioners from China and foreign countries have increasingly established commercial relations more than ever before. With the prosperity of commercial exchanges, commercial disputes have also sharply increased. Guaranteeing the efficiency of dispute resolution is vital for improving and better realizing the BRI strategy. As of June 1, 2021, 43 countries along the Belt and Road route have signed the Singapore Convention on Mediation ${ }^{[9]}$, thus making its future application highly realistic. It should be noted that the Convention exempts the recognition procedure of the concerning settlement agreement in a domestic court, and provides a guarantee for cross-border enforcement, which to a certain extent, would eliminate the concerns on the uncertainty in the enforcement of disputing parties. Hence, promoting the ratification of the Convention would facilitate investors to participate in the construction and development of BRI with relatively worry-free dispute resolution mechanism and barely any cross-border enforcement issues ${ }^{[10]}$. Moreover, the connotation of harmony embodied in the commercial mediation system shares the same root with the idea of "Consultation, Contribution, and Shared Benefits", which are the golden principles of BRI, thus granting commercial mediation more solid ground in the context of the development of BRI. The ratification and implementation of the Convention would definitely be a legal dividend for BRI participants and promote its development. 


\section{Conclusion}

China has been actively developing the commercial mediation system in a professionalized and internationalized method where it has made achievements based on which the Singapore Convention on Mediation has solid ground to adopt and implement. It is vital and a prerequisite for Chinese authority to accelerate the ratification process of the Convention for the realization of its purpose of promoting international economic development.

\section{Disclosure statement}

The author declares that there is no conflict of interest.

\section{References}

[1] Singapore Convention on Mediation: Status. https://www.singaporeconvention.org/convention/status/

[2] Yang Y, Ding JZ, Zhao L, 2017, Annual Observation of Commercial Mediation in China, Annual Observation of Commercial Dispute Resolution in China. China Legal Publishing House, (06): 37.

[3] Zhu FH, Gu J, Guo YN 2020, Annual Observation of Commercial Mediation in China, Annual Observation of Commercial Dispute Resolution in China. China Legal Publishing House, (09): 38.

[4] Menon S, 2015, "International Commercial Courts: Towards a Transnational System of Dispute Resolution", Opening Lecture for the DIFC Courts Lecture Series. https://www.supremecourt.gov.sg/d ocs/default-source/default-document-library/media-room/opening- lecture---difc-lecture-series2015.pdf

[5] Góme KF, 2019, The Role of Mediation in International Commercial Disputes - Reflections on some Technological, Ethical, and Educational Challenges, Mediation in International Commercial and Investment Disputes. Oxford University Press, Oxford, (1): 5.

[6] Kaufmann-Kohler G, 2004, "Enforcement of Awards - A Few Introductory Thoughts" [van den Berg AJ, Ed.], May, 2004: ICCA Congress Series No.12. New Horizons in International Commercial Arbitration and Beyond (The Hague: Kluwer Law International, 2004), Beijing.

[7] Hwang MSC, Yeo CT, Recognition and Enforcement of Arbitration Awards, in The Asian Leading Arbitrators' Guide to International Arbitration, 407-63.

[8] Fei N, Jiang H, Liu J, 2019, Annual Observation of Commercial Mediation in China, Annual Observation of Commercial Dispute Resolution in China. China Legal Publishing House, (07): 29.

[9] Chen J, 2020, The Construction of China's International Reconciliation Agreement Granting Relief System-Regarding the signing of Singapore Mediation Convention as a Chance. Journal of Southeast University Philosophy and Social Science, (2): 94.

[10] Tang X, 2021, Challenge and Response for China Granting Singapore Mediation Convention, Commercial Arbitration and Mediation. China Academic Journal Electronic Magazine, (1): 48. 